Revista Monografias Ambientais - REMOA v. 15, n.1, jan-abr. 2016, p.228-246

Revista do Centro de Ciências Naturais e Exatas - UFSM, Santa Maria

\title{
RECUPERAÇÃO DE ÁREAS DEGRADADAS, ADUBAÇÃO VERDE E QUALIDADE DA ÁGUA
}

\author{
Degraded areas recovery, green manure and water quality
}

\author{
Evaldo de Melo Ferreira' ${ }^{1}$, Michel de Paula Andraus ${ }^{2}$, Aline Assis Cardoso ${ }^{1}$, \\ Lays Fabiana dos Santos Costa ${ }^{1}$, Lucas Morais Lôbo ${ }^{3}$, Wilson Mozena Leandro ${ }^{1}$ \\ ${ }^{1}$ Universidade Federal de Minas Gerais \\ ${ }^{2}$ Universidade Federal de Goiás \\ ${ }^{3}$ Universidade Anhanguera
}

\begin{abstract}
Resumo
O presente trabalho teve como objetivo principal realizar uma compilação de referências da literatura nacional $e$ internacional relacionadas à recuperação de áreas degradadas. Alguns dos termos de indexação utilizados foram: áreas de preservação permanente em recuperação, adubos verdes, feijão guandu, crotalária, estilozantes e qualidade da água. As bases de dados utilizadas foram o SciELO, Scopus e também Science Direct. No total foram utilizadas mais de 100 referências, sendo grande parte dos artigos publicados no ano de 2014 e outros em 2015 em revistas científicas da área. Em se tratando da busca por trabalhos que abordem adubos verdes em consórcio com nativas do Cerrado, não foram encontradas referências, ainda que o esgotamento das referências fosse algo buscado.
\end{abstract}

Palavras-chave: Meio ambiente. Sistemas naturais degradados. Qualidade ambiental.

\section{Abstract}

This study aimed to carry out a compilation of references to national and international literature related to the recovery of degraded areas. Some of the index terms used were: permanent preservation areas in recovery, green manure, feijã guandu, crotalária, estilozantes and water quality. The databases used were the SciELO, Scopus and Science Direct also. In total were used more than 100 references, most of the articles published in 2014 and others in 2015 in scientific journals of the area. In the case of the search for work addressing green manure intercropped with native Cerrado, references were found, although the exhaustion of the references were something sought.

Keywords: Environment. Degraded natural systems. Environmental quality. 


\section{Introdução}

A presença de espécies arbóreas em determinada área é essencial para o correto equilíbrio dos ecossistemas em que essas estão inseridas. De acordo com Neri et al. (2013) a vegetação do Cerrado é a maior savana neotropical e se estende ao longo de um milhão e meio de quilômetros quadrados na América do Sul tropical. Magalhães et al. (2013) afirmam que a substituição da floresta por outro tipo de uso do solo pode levar a perdas significativas na matéria orgânica do solo, alterando sua dinâmica e como consequência alterando as entradas e saídas de nutrientes do sistema. As Áreas de Preservação Permanete (APPs) auxiliam na preservação dos recursos hídricos, na estabilidade geológica e da fauna e flora existente, além de facilitar o fluxo gênico entre espécies (BRASIL, 2012).

As modificações causadas pelo homem são alguns dos fatores que mais influenciam as características de determinada área. Em áreas próximas a corpos hídricos e naquelas consideradas como zonas húmidas onde terrenos hidromórficos se fazem presentes, quando as plantas não são nativas da área, seu desenvolvimento pode ser drasticamente alterado (HU et al., 2015). Em áreas de Cerrado o desmatamento ainda é considerado um grande problema a ser controlado. Entre todos os outros, esse é o com mais rápida perda de vegetação natural (TRANCOSO et al., 2014).

Um dos principais fatores de degradação ambiental é a falta de políticas de uso e ocupação do solo. Com relação as políticas de regulamento de uso do solo e preservação de APPs, por exemplo, estudiosos acreditam que a conservação restrita a uma área pode simplesmente deslocar uso e atividades em outro lugar, resultando em aumento do desmatamento no entorno. Isso pode anular ou reduzir os resultados positivos de tal regulamentação (BRUGGEMAN et al., 2015).

Na redução da competição entre as espécies nativas e espécies invasoras, uma das opções é o uso de adubos verdes. Esses também auxiliam na fixação de nutrientes importantes na sobrevivência das plantas, além de sequestrar o carbono a ser emitido para a atmosfera que geralmente é fonte do desequilíbrio ambiental, seja pela deposição de material vegetal resultante dos desmatamentos, ou pela lixiviação de matéria orgânica no solo (POEPLAU \& DON, 2015). Outro fator do solo influenciado positivamente pela adubação verde (além dos componentes 'macro' tais como vegetação e macro fauna) é a microbiota, sendo isso avaliado por meio da respiração microbiana, por exemplo (SHRESTHA et al., 2015).

Em áreas de APP onde houve algum processo de degradação, uma das formas de recuperação é o uso da revegetação com espécies nativas da área, em que muitas vezes não são arbóreas, mas também podem ser arbustos ou gramíneas, que quando utilizadas em processos de revegetação, devem ter seu desenvolvimento monitorado, evitando, por exemplo, a morte de algum indivíduo e a substituição desse. Algo importante é o estudo da dinâmica das árvores em longo prazo, sendo isso apontado como fator limitante na regeneração natural de florestas (BOUMAN, 2015).

O presente trabalho teve como objetivo principal realizar uma compilação de referências da literatura nacional e internacional relacionadas à recuperação de áreas degradadas. 


\section{Material e Métodos}

Com o objetivo de conhecer quais as investigações técnico-científicas relacionam o uso de adubos verdes em consórcio com nativas do Cerrado em recuperação de áreas degradadas, além do estado da arte relacionado à temática qualidade da água, foram feitas buscas em periódicos nacionais e também internacionais. As bases de dados utilizadas foram o SciELO, Scopus e também Science Direct.

No total foram encontrados 107 trabalhos, sendo grande parte dos artigos publicados no ano de 2014 e outros em 2015 em revistas científicas da área. Entre outras, as principais palavras-chave utilizadas foram: degraded areas recovery, green manure e water quality. Os percentuais para o volume de trabalhos encontrado de acordo com a área de estudo, é detalhado no gráfico a seguir (Figura 1):

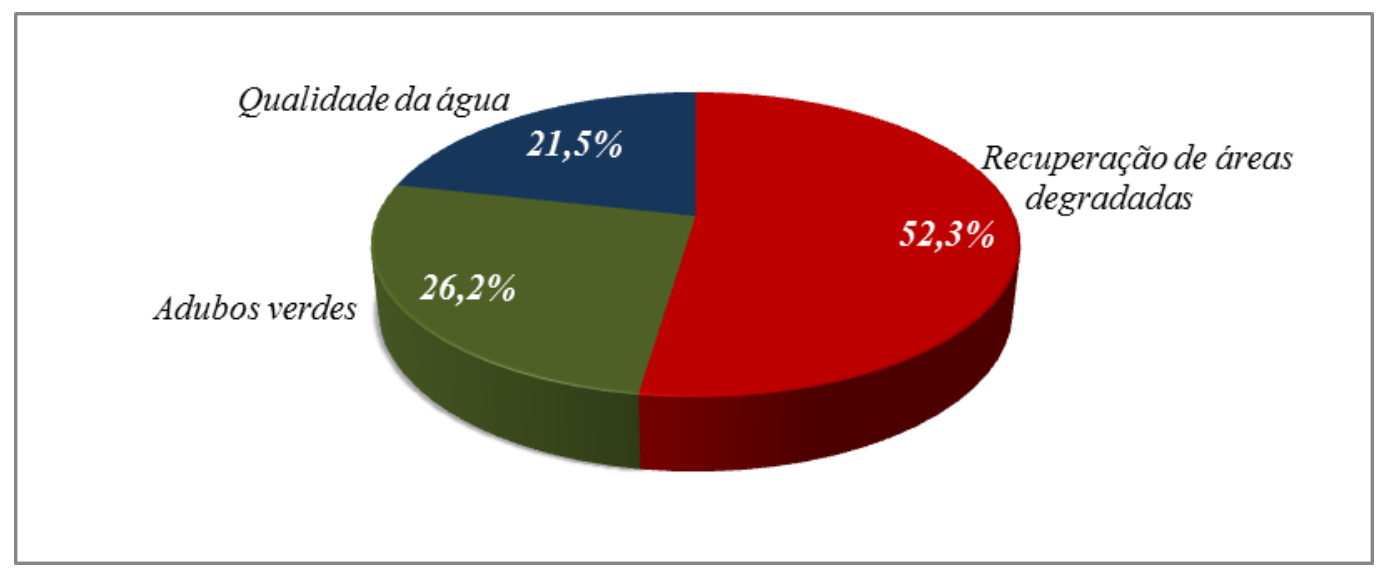

Figura 1 - Percentuais dos trabalhos encontrados de acordo com o assunto buscado. Fonte: Autores (2015).

\section{Recuperação de áreas degradadas}

A busca por novas terras a serem utilizadas para fins agrícolas é um fenômeno presenciado por vários países. Estudiosos explicam isso em razão da demanda por alimentos, agroenergias e matérias-primas, estando o assunto presente na grande imprensa e tendo sido fruto de debates acadêmicos internacionais (SAUER \& LEITE, 2012).

Devido a essa expansão da fronteira agrícola, alguns problemas passaram a surgir. Nos Estados Unidos da América (um dos maiores produtores de grãos), por exemplo, ecólogos têm levantado a necessidade de pensar sobre as perdas de pastagens e "zonas de humidade", devido as mudanças provocadas pelas práticas agrícolas (JOHNSTON, 2014).

Um dos ecossistemas mais afetados por essas alterações são os tropicais. Com a magnitude do problema, acredita-se em na agricultural bomb, cuja ânsia por detonação, criar desafios profundos para o bem-estar humano e para a conservação ambiental (LAURANCE et al., 2014).

As erosões são um dos resultados da explosão da bomba agrícola. No Estado de Goiás, uma das erosões mais conhecidas é a Chitolina. Na área onde hoje se encontra o problema, o cultivo da soja foi iniciado em 1981 com a utilização de curvas de contenção destinadas a eliminar o escoamento superficial e a erosão. A vegetação inicial era o Cerrado, com predominância de gramíneas, sendo que no período de introdução da agropecuária, ocorreram poucas mudanças no ecossistema, particularmente no que se refere à pastagem, pois o cerrado era utilizado como pasto (GOMES et al., 2011).

As erosões ocorrem naturalmente ou de forma induzida, acelerada pela ação antrópica (MARIOTI et al., 2013). Em bacias hidrográficas, o aumento das pressões sobre os recursos terra e água leva a tensão não só sobre os recursos naturais, mas também sobre as populações humanas e sobre as indústrias que terão o abastecimento afetado (Hunink et al., 2012). As taxas de desgaste do solo vêm assumindo proporções espantosas, com enormes implicações de ordem física, financeira e social (OLIVEIRA et al., 2010). 
As modificações negativas em ecossistemas naturais causam degradação ambiental intensa em diferentes áreas abrangidas. Em estágios avançados, alguns dos principais problemas são o transporte de sedimentos, a remoção de nutrientes, de carbono orgânico e o arraste de agroquímicos para fora dos sistemas agrícolas. Além dos impactos ambientais anteriormente citados, isso também resulta no decréscimo de produtividade (AVANZI et al., 2013). As ravinas e sulcos são outros integrantes dos processos erosivos, ocorrendo a diminuição da qualidade da estrutura do solo, podendo ser caracterizada como superficial, com o aparecimento de finas crostas, ou em subsuperfície, com o surgimento de camadas compactadas, resultando em menores taxas de infiltração de água e maiores de escoamento superficial e de erosão, o que irá acelerar mais ainda o processo de degradação do solo (PORTELA et al., 2010).

A erosão do solo é um risco tradicionalmente associado com a agricultura, tendo efeitos a médio e longo prazo sobre a produtividade do solo e agricultura sustentável. Outro dano ambiental causado pela erosão é a poluição de cursos hídricos com pesticidas presentes no solo e o aumento de inundações (SHI et al., 2012).

Em se tratando de pastagens e de outras coberturas vegetais, a conservação do solo é um dos serviços ambientais mais importantes prestados por essas culturas ( $\mathrm{Lu}$ et al., 2013). Além do desmatamento, entre as práticas de manejo que diretamente influenciam o processo erosivo causado pela água da chuva, estão as operações de preparo do solo e semeadura das culturas. Essas determinam as condições físicas de superfície e subsuperfície (VOLK \& COGO, 2014).

O preparo reduzido, o uso de plantas de cobertura e de faixas de proteção com grama, são práticas que provaram serem bem sucedidas para o controle da erosão do solo, o que traz melhorias na qualidade ambiental (WAUTERS et al., 2010).

Em APPs, as arbóreas com todo seu sistema de (raiz, tipo de folha, ângulo de inserção das folhas no colmo, quantidade e espessura das hastes e o hábito de crescimentoł interrompem a erosão hídrica, interceptando as gotas de chuva que caem (BERTOL et al., 2013). Em áreas que sofreram impactos negativos sobre suas características naturais, algumas técnicas devem ser aplicadas com o objetivo de acelerar os processos de regeneração.

No controle de erosões as práticas mecânicas mais comuns são os terraços, onde pequenas barragens de terra são construídas com o fim de conter o carreamento de solo, sendo utilizado para isso os maquinários. Nessas obras de engenharia, é necessário o conhecimento das características climáticas da área, do tipo de solo, da topografia do terreno e do maquinário ideal a ser utilizado (MIRANDA et al., 2012).

Em APPs as técnicas conservacionistas vegetativas possuem como foco principal a restauração vegetal. Um dos estágios iniciais desse trabalho, são os levantamentos das espécies anteriormente presente no ambiente, junto ao entendimento das formas de uso e estádio de conservação. A realização de levantamentos florísticos e, ou, fitossociológicos é imprescindível para subsidiar tais ações, sendo que esses visam a obtenção do conhecimento prévio da composição das formações vegetacionais, fornecendo subsídios para estudos mais detalhados e dados básicos (FERREIRA et al., 2011a).

Na recuperação de áreas degradadas, algumas das principais funções das espécies arbóreas são: reabilitação do solo, contenção de erosões, atração de polinizadores, recarga do lençol freático por meio das raízes, atração de fauna local e restabelecimento da beleza cênica. Na escolha das espécies deve-se, preferencialmente, utilizar mudas iguais ou de comportamento similar as espécies arbóreas anteriormente presentes na área.

De acordo com Daronco et al. (2013) a autossustentabilidade de ecossistemas florestais depende da manutenção dos processos de regeneração natural das espécies vegetais, especialmente arbóreas, que formam a estrutura que abriga todas as outras espécies e cria condições ambientais para o desencadeamento dos processos ecológicos. Uma das opções para o conhecimento das influências das espécies arbóreas em área de reflorestamento é a estimativa de biomassa. Em plantios de restauração, são poucos os estudos envolvendo modelagem da biomassa e do carbono, deixando assim uma lacuna de informações a respeito do potencial dessas florestas como sumidouros de carbono (MIRANDA et al., 2011b). 
Espécies arbóreas possuem seu sistema influenciado pela precipitação, temperatura, relevo e tipo de solo. Em estudo realizado por Bauer (et al., 2012) com espécies de floresta secundária semidecídua no Sul do Brasil, foi mostrada a relação entre o desenvolvimento das árvores e fatores tais como temperatura e o fotoperíodo.

Similar a árvores de outros biomas, espécies do cerrado (um dos biomas mais influenciados pelas mudanças antrópicas) dependem dos serviços ambientais prestados pela fauna, porém as rápidas modificações provocadas pelo homem ameaçam essas espécies (AGUIAR et al., 2014). A sucessão vegetacional é um dos fenômenos mais importantes para a manutenção da cobertura verde. A morte de árvores mais velhas ou a queda de árvores por vento ou outras causas quaisquer, a abertura de clareiras e seus processos associados, são alguns dos fenômenos que fazem parte disso (VENTUROLI et al., 2011). Segundo Assunção et al. (2011) os mecanismos de dispersão, essenciais na distribuição natural das espécies, requer interações entre as plantas e seus dispersores e podem variar conforme os hábitos de crescimento.

Um exemplo de espécie com bom potencial para utilização em áreas em recuperação, é o Dipteryx alata, popularmente conhecido como baru. Sendo esta uma planta arbórea que ocorre principalmente em áreas cujos solos apresentam média fertilidade, sendo útil para diversos fins (AJALLA et al., 2012).

\section{Adubos verdes}

Os adubos verdes são plantas com características que possibilitam a melhoria em médio e longo prazo de propriedades físico-químicas do solo, redução na competição entre espécies, além do cultivo para fins comerciais. Em regiões semiáridas, os adubos são cultivados para utilização como cobertura morta em áreas com histórico de manejo inadequado do solo e baixa precipitação. Alguns exemplos de adubos verdes são Cajanus cajan (feijão guandu), Crotalaria juncea (crotalária) e Stylosanthe multilinea (estilozantes). Em APPs em processos de revegetação, essas espécies podem ser utilizadas em consórcios com espécies arbóreas (Figura 2).

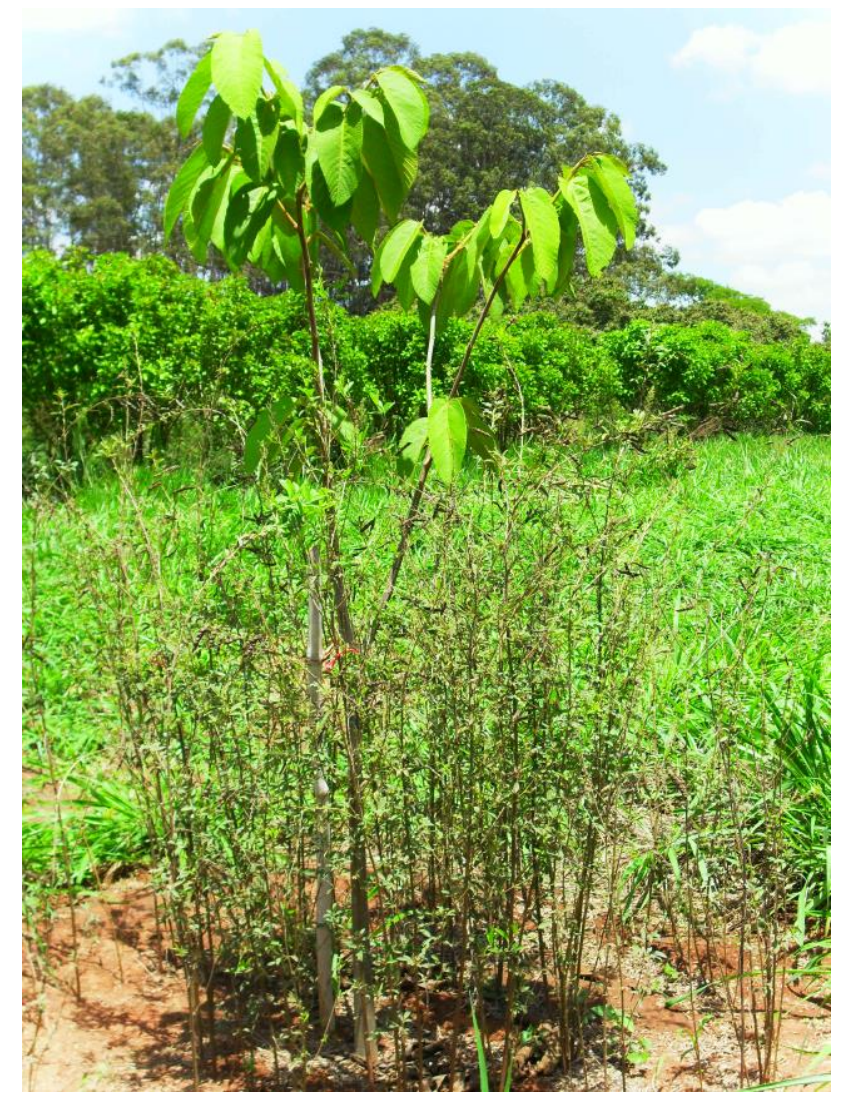

Figura 2 - Adubos verdes em consórcio com nativa do Cerrado. Fonte: Autores (2014). 
Em estudo realizado com o objetivo de conhecer o comportamento dos adubos verdes em regiões secas, foram observadas que a cobertura plena do solo foi alcançada pelo calopogônio, amendoim forrageiro e cudzu tropical. O calopogônio conferiu maior capacidade de retenção da umidade e inibição das plantas espontâneas. Em todos os tratamentos com leguminosas a temperatura do solo foi inferior à testemunha, a partir dos 120 dias de ciclo (TEODORO et al., 2011).

Em sistemas de plantio direto (SPD), os adubos podem ser utilizados como cultura pré-safra. Espécies leguminosas têm sido utilizadas como adubos verdes, assumindo importante papel para o aumento da quantidade e da qualidade da matéria orgânica do solo (LIMA et al., 2012).

Algumas espécies de adubos verdes apresentam um bom desempenho para fins específicos e outras são adaptáveis a diferentes condições. O Canavalia ensiformis (feijão-de-porco), vegetal resistente as adversidades climáticas, é adaptável a condições ambientais que o fazem suportar desde o clima árido e seco das regiões semiáridas até o de regiões com florestas tropicais (TEODORO et al., 2011).

Em estudo realizado utilizando feijão-de proco, com o objetivo de levantar qual a comunidade de plantas daninhas no cultivo de milho em monocultivo e em consórcio, com diferentes espécies de Fabaceae, observou-se que o monocultivo apresentou maior diversidade de plantas daninhas em relação ao consórcio e resultando em maior peso da matéria seca de plantas daninhas de folhas estreitas e plantas daninhas mais altas $\mathrm{E}$ que o monocultivo e a capina apresentam plantas de milho com maior altura e peso de matéria seca (OLIVEIRA et al., 2014).

A fitorremediação de agrotóxicos é outra aplicação dos adubos verdes. Conforme estudo realizado por Monquero et al. (2013) a espécie C. cajan mostrou-se eficiente na remediação de solos contaminados com diclosulam, sendo esse um herbicida do grupo químico triazolo pirimidina sulfonanilidas, indicado para controle de dicotiledôneas em pré-semeadura incorporada ou em préemergência na cultura de soja.

Em uma investigação onde o objetivo foi avaliar a supressão de plantas daninhas e a produção de sementes de Crotalaria juncea, sob diferentes métodos de semeadura esta independentemente da disposição de semeadura utilizada, suprimiu o desenvolvimento da comunidade de plantas daninhas. Apresentando bom desempenho, independente da sua distribuição na área (TIMOSSI et al., 2011).

O uso de adubos verdes também já foi testado na produção de tomate orgânico. Sendo as As espécies utilizadas: Crotalaria juncea, Avena sativa, Stizolobium aterrimum, Canavalia ensiformis e Lolium multiflorum. Nesse estudo as diferenças nos valores encontrados foram devido, principalmente as cultivares (TOLEDO et al., 2011).

Com relação a propriedades microbiológicas do solo, em alguns casos, dependendo do tempo de avaliação, a cobertura verde pode apresentar diferentes resultados. Em avaliações dos efeitos do tipo de manejo do solo e das plantas de cobertura nos indicadores microbianos da qualidade do solo, foi desenvolvido um experimento em condições de campo, com feijoeiro comum e milho, cultivados sob semeadura direta e preparo convencional do solo, após crotalária, mucuna preta, feijão guandu, feijão de porco, sorgo e pousio (plantas espontâneas), em que as plantas de cobertura apresentaram efeito menos evidentes nos indicadores de qualidade do solo microbiológicos, em comparação com os sistemas de manejo do solo (FERREIRA et al., 2011).

De acordo com Tavares et al. (2011): "organismos de solo desempenham um importante papel em cultivos orgânicos de Crotalaria juncea (Fabaceae) e estão associados com a conservação natural do ambiente".

$\mathrm{Na}$ avaliação do uso dessas plantas junto com a cana-de-açúcar, foi estudado efeito do cultivo prévio de leguminosas sobre a produtividade e lucratividade da cana-de-açúcar, onde foram determinados a produtividade de biomassa, o acúmulo de nutrientes das leguminosas, a ocorrência natural de fungos micorrízicos arbusculares, bem como o efeito das leguminosas sobre a população de nematoides do gênero Pratylenchus à cana-de-açúcar. Após cinco cortes da cana-de-açúcar o melhor desempenho foi notado no tratamento com cultivo prévio de crotalária juncea, o qual promoveu incrementos de $30 \%$ e $35 \%$ na produtividade de colmos e de açúcar respectivamente e o melhor desempenho econômico (AMBROSANO et al., 2011). 
Em outro estudo com o uso de crotalaria juncea em área de cultivo de repolho, as raízes leguminosas não representaram conteúdo significativo de $\mathrm{N}$, sugerindo tanto baixa oferta $\mathrm{N}$ pelas raízes e N imobilização na matéria orgânica do solo e da biomassa microbiana (VARGAS et al., 2013).

$\mathrm{Na}$ avaliação da taxa de decomposição e da velocidade de liberação de macronutrientes e Si da fitomassa do consórcio crotalária + milheto, em função do tempo após manejo, sem e com fragmentação, a fragmentação da fitomassa do consórcio crotalária + milheto aumentou a taxa de decomposição e a liberação de N, P, Ca e S (COSTA et al., 2014).

Ao avaliar o efeito de diferentes adubos orgânicos em associação ou não com adubo verde na produção de folhas de Ocimum selloi Benth., planta nativa do Brasil, não foi observado incremento nos resultados pela associação com a Crotalaria juncea (MORAIS \& BARBOSA, 2012). Espécies tais como crotalária juncea e feijão-de-porcoforam eficientes no controle das perdas de solo, água e nutrientes por erosão hídrica, visando à conservação do solo (CARDOSO et al., 2012).

Algo estudado foi o efeito das coberturas verdes precedentes sobre a necessidade de adubação nitrogenada da cultura do milho, durante diferentes anos agrícolas em sistema de plantio direto. $\mathrm{O}$ cultivo de milho após crotalária apresentou melhor desempenho e menor demanda de adubação nitrogenada, quando comparado ao cultivado após milheto (LEAL et al., 2013).

Na cultura do trigo, a utilização de diferentes coberturas vegetais pode reduzir a necessidade de fertilizantes nitrogenados em cobertura, sendo que o cultivo de trigo em sucessão aos resíduos vegetais de guandu, crotalária e milheto junto à crotalária pode apresentar maior produtividade de grãos do que em sucessão ao pousio (MELERO et al., 2013).

Ao avaliar a produção de fitomassa e as taxas de decomposição e liberação de macronutrientes e de silício, nos resíduos vegetais de crotalária e milheto, em cultivo solteiro e consorciado, foi observado maior acúmulo de Ca pela crotalária (SORATTO et al., 2012), algo interessante de ser avaliado em SPD, pois dessa forma, custos podem ser reduzidos.

Em relação à massa da parte aérea ou da planta inteira de crotalária no cultivo de repolho, foi reduzida a necessidade de adubação com $\mathrm{N}$-mineral em $50 \%$. Áreas em que foram deixadas a parte aérea ou a planta inteira de crotalária resultaram em maiores efeitos residuais sobre o segundo cultivo do que a adubação com $\mathrm{N}$-mineral. O cultivo sucessivo sobre as raízes da leguminosa não resulta em efeito residual diferente do proveniente da adubação mineral com 50 ou 100\% da recomendação da adubação N (VARGAS et al., 2011).

No SPD de alface americana com o uso de cobertura dessecadas ou roçadas em dois cultivos sucessivos, a mucuna apresentou desempenho superior em relação à cobertura com milheto, C. juncea, C. spectabilis e C. cajan no primeiro cultivo da alface em plantio direto. O excesso de palha da C. juncea apresentou elevado controle de plantas daninhas mas dificultou o estabelecimento da alface (HIRATA et al., 2014).

Existem estudos que relacionam o uso de crotalária na cultura do arroz, considerado um dos mais importantes na nutrição humana. Avaliando-se diferentes coberturas vegetais, doses de $\mathrm{N}$ na presença e ausência da inoculação de sementes com A. brasilense no arroz de terras altas cultivado em SPD no desenvolvimento e na produtividade da cultura, os cultivos antecessores influenciaram a produtividade do arroz (GITTI et al., 2013).

Em processos de fitorremediação, adubos verdes tais como o feijão-de-porco possuem, por exemplo, potencial para ser utilizada em programas de fitoextração de $\mathrm{Cu}$ em solos. O Cu teve maior acúmulo no sistema radicular e, portanto, translocado em baixa proporção para a parte aérea, o que embora seja considerada uma estratégia das plantas para aumentar a tolerância ao metal, será limitnte para o emprego da fitoextração (ZANCHETA et al., 2011).

A fitorremediação busca por soluções para reduzir o potencial de contaminação do solo e dos recursos hídricos com sulfentrazone, tem-se pesquisado a efetividade da fitorremediação, utilizando plantas como agente descontaminante. Para tanto, crotalária e mucuna-preta foram algumas das espécies testadas (MADALÃO et al., 2013).

Em Taiwan espécies de adubo verde tais como Sesbanin roxburghii Merr., Crotalaria juncea L. e Brassicae campestres L. variedade chinensis, foram utilizadas no controle de pragas tais como a Lepidoptera, Noctuidae. O estudo teve como um dos resultados a necessidade da escolha criteriosa 
das plantas a serem utilizadas no controle natural de pragas (TUAN et al., 2014). Entre outros fatores, um dos principais motivos para isso é a prevenção de impactos ambientais na área de utilização das plantas. Para uma melhor inserção de nutrientes pelos adubos verdes, pode-se realizar a incorporação das plantas ao solo, devendo essa ser feita entre oito e 10 semanas após o plantio. $\mathrm{O}$ aporte de $\mathrm{N}$ ao sistema solo/planta é estimado entre 100 e $300 \mathrm{~kg} \mathrm{~N} / \mathrm{ha} / \mathrm{ano}$ (SILVA et al., s/d). Os adubos verdes também são eficientes na redução dos níveis de compactação do solo (Figura 3).

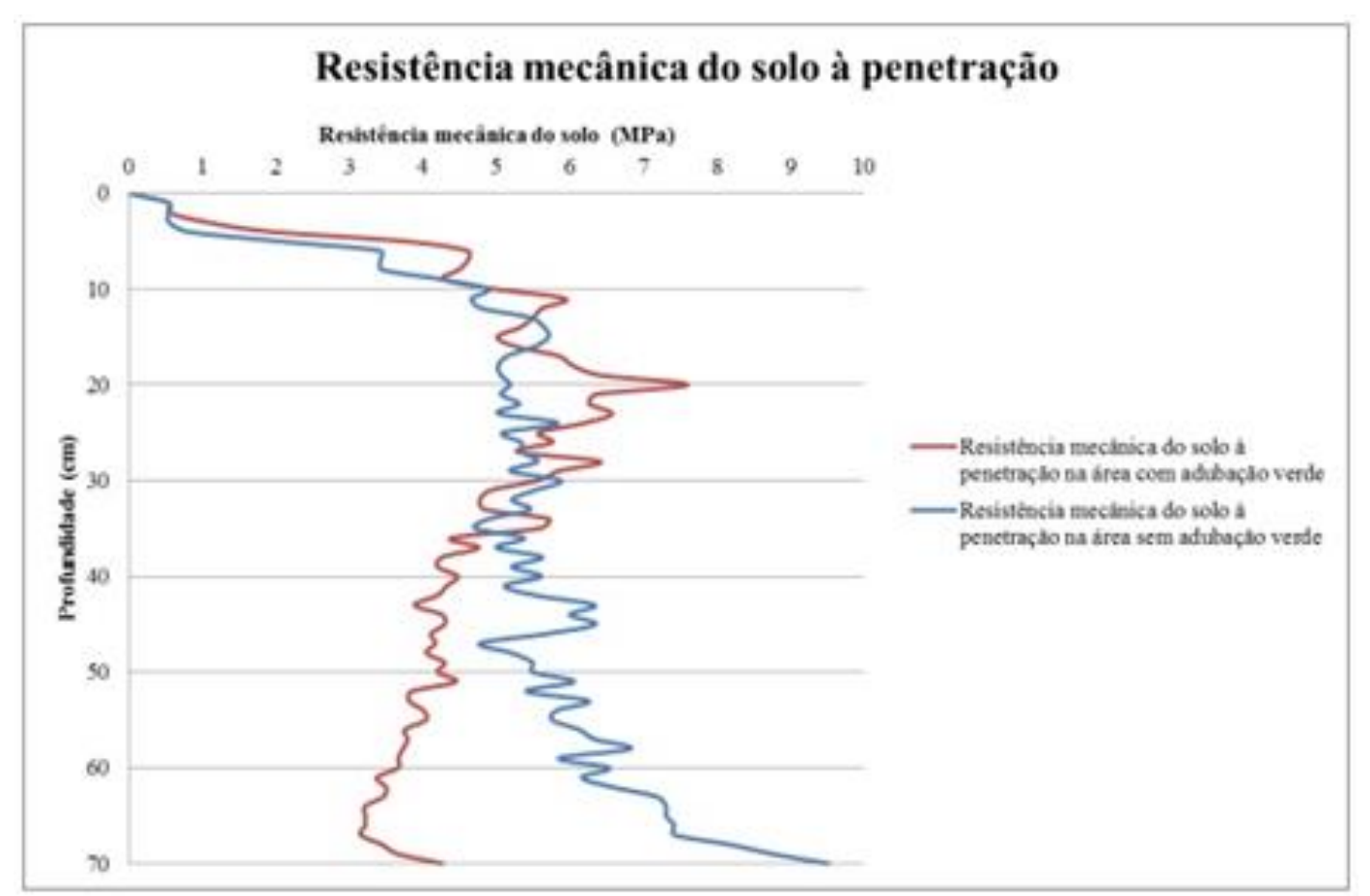

Figura 3 - Teste realizado com penetrômetro de impacto em latossolo vermelho em recuperação. Fonte: Autores (2014).

\section{Cerrado}

De acordo com Vieira et al. (2014) o Estado de Goiás, com $340.117 \mathrm{Km}^{2}$, encontra-se completamente inserido no bioma Cerrado, representando, portanto, cerca de $20 \%$ dos estimados dois milhões de $\mathrm{Km}^{2}$ deste importante domínio ecogeográfico.

A interiorização da capital da República e das respectivas políticas de ocupação para a região central do país, incentivando o desenvolvimento da pecuária e da agricultura extensiva, como a soja, milho, algodão e, mais recentemente, da cana-de-açúcar, são as principais alterações (OLIVEIRA et al., 2012).

No século 19, a região de domínio de Cerrado era considerada pobre para produção agrícola, e a prática da pecuária não promovia degradação desse ambiente, porém, com a evolução tecnológica, o domínio de Cerrado passou a ser bioma altamente produtivo (SILVA et al., 2011).

De acordo com Rosolen et al. (2012) imensas áreas de vegetação original foram desmatadas por corte e queima e substituídas por monoculturas de grãos (soja e milho, principalmente), algodão, pastagens manejadas associadas com pastagens degradadas (naturais), entre outros. Quando ocorre a supressão vegetal, o efeito estufa é agravado, sendo esse um processo natural ocasionado pelo acúmulo de gases na atmosfera, formando uma barreira que aprisiona a radiação infravermelha.

O Brasil é um dos maiores exportadores de carne bovina no mundo, e tal atividade ocupa a maior área do território brasileiro. É necessário conciliar o aumento da produção de carne a partir de sistemas com baixa emissão de $\mathrm{CO}_{2}$, ou seja, que sequestre $\mathrm{CO} 2$ no solo, ou que seja capaz de reduzir o impacto sobre o aquecimento global (ROSENDO \& ROSA, 2012). 
Na implantação da agricultura moderna, os espaços prioritários para investimentos de capital no Cerrado foram as áreas de chapada, ou chapadões. Essas áreas são dotadas de excelentes recursos hídricos, que possibilitam a irrigação de culturas no período seco entre os meses de maio a setembro. Os fatores físicos foram importantes para a expansão da fronteira agrícola, pois, ao se apropriar, o capital não tem interesse apenas na terra, mas também no que ela contém de outros recursos naturais tais como água, relevo e clima (MATOS \& PESSÔA, 2012). Um dos fenômenos mais importantes para o cerrado são as queimadas. Em estudo realizado com o objetivo de avaliar a influência dos elementos climáticos e dos regimes de queimadas nos padrões de fenologia vegetativa e reprodutiva das espécies arbóreas Caryocar brasiliense Cambess e Enterolobium gummiferum (Mart.) J.F.Macbr, o regime de queimada em que as árvores foram submetidas, não alterou as fenofases ou o potencial reprodutivo de E. gummiferum, mas retardou a troca das folhas e inibiu a produção de diásporos de Caryocar brasiliense, mostrando quão sensível o bioma é em relação aos fatores externos (FRANÇOSO et al., 2014).

Em levantamentos fitossociológicos em área de Cerrado stricto senso no Estado de Mato Grosso do Sul, onde existem alterações antrópicas, um dos principais resultados foi que a área analisada é capaz de se recuperar naturalmente através da retirada dos principais fatores de pressão: acesso do gado ao local (isolamento da área com cercas), proibição da retirada de madeira nativa e não ocorrência de fogo nos últimos cinco anos, além de ser verificada a importância do estabelecimento de uma unidade de conservação no local (FINA \& MONTEIRO, 2013).

Atenção especial deve ser dada ao cerrado sensu stricto, que representando esse, cerca de $70 \%$ do bioma, sendo que a conversão indiscriminada para outros fins acarreta em grandes modificações no estoque de carbono presente no ecossistema (PAIVA et al., 2011). Em áreas onde houve a supressão da vegetação nativa para o uso do solo na criação bovina, quando a pastagem está bem manejada, pode-se melhorar a qualidade química do solo, por meio do aumento nos teores de $\mathrm{P}, \mathrm{K}, \mathrm{Ca}$ e $\mathrm{Mg}$ e da CTC do solo e incrementa a biomassa microbiana do solo (LEITE et al., 2013).

No bioma Cerrado os solos dominantes são Latossolos (Latossolos), sendo os SPD introduzidas em meados dos anos 80 . Esses são bons fornecedores de matéria orgânica para o solo, a qual está presente em níveis médios entre ( 2 e 3 dag kg-1 ), sendo um componente fundamental para regular a fertilidade do solo e responsável por reservas de nutrientes (CARVALHO et al., 2014).

Para alguns componentes químicos, os solos do Cerrado podem apresentar características específicas. Em estudo realizado por Campos et al. (2013), os teores médios de As e Cd decresceu na seguinte ordem das sub-regiões: leste de Goiás > Triângulo Mineiro > nordeste de MG. Com relação a determinados componentes como o P, o manejo desse elemento é algo comum, feito por exemplo, por meio da adubação fosfatada com aplicações no sulco de semeadura de fontes solúveis de P (NUNES et al., 2011).

\section{Monitoramento da qualidade da água}

A água é essencial para a manutenção da vida em suas diferentes formas e apresenta múltiplos usos, entre eles a dessedentação humana e a utilização nos ciclos naturais, de modo a garantir o equilíbrio ecológico. A escassez de água potável, limpa e segura ainda é um dos principais fatores de mortalidade em países em desenvolvimento (BOUTILIER et al., 2014).

Os usos e ocupações do solo são um dos principais fatores interferentes na qualidade da água superficial, sendo que a gestão da qualidade da água está baseada na minimização ou mitigação dos danos ambientais (BARRINGTON et al., 2013). O monitoramento da qualidade dos recursos hídricos é dever do poder público e tem como um dos principais resultados positivos, a possibilidade de ação antes que o impacto ambiental ocorra.

Os usos e ocupações do solo, são transformados constantemente ao longo do tempo devido as atividades humanas. Quando o solo não possui cobertura vegetal o carreamento de suas partículas é facilitado. Como consequência disso, tem-se a entrada de espécies químicas (solúveis e adsorvidas) transportadas no escoamento superficial que causam a degradação dos corpos hídricos, provocando o 
enriquecimento da água com nutrientes agentes de eutrofização dos mananciais, além de provocar a morte de peixes e também o assoreamento (PINHEIRO et al., 2013).

O uso agrícola do solo em países em desenvolvimento ainda tem sido um dos principais fatores intervenientes na qualidade da água. Outra interferência que o uso do solo possui é sobre as plantas, afetando a capacidade de manutenção de determinados nutrientes e de carbono, além de afetar o papel do solo como um regulador do ciclo hidrológico (KUWANO et al., 2014).

Os impactos decorrentes dos usos em que o solo é submetido alteram os ciclos hidrológicos e de transporte de sedimentos, o escoamento superficial, a vazão máxima de cheia, os fluxos de base, a recarga subterrânea, a umidade do solo e o volume de erosão e sedimentação (PERAZZOLI et al., 2013). As alterações antrópicas também estão relacionadas a atributos como a compactação e permeabilidade da área, provocando alterações associadas a práticas de manejo em graus variados sobre os atributos do solo (LIMA et al., 2013).

É essencial o conhecimento das alterações no solo de acordo com os usos e manejos aos quais esse é submetido, sendo que os acompanhamentos temporais dessas propriedades e em diferentes sistemas de manejo podem determinar, de maneira mais conclusiva, a importância dessas propriedades na avaliação da qualidade dos solos (BONO et al., 2013). O monitoramento ambiental em bacias hidrográficas procura analisar aspectos relevantes que permitam caracterizar as mudanças que ocorrem no uso e ocupação do solo, tornando possível avaliar os efeitos das atividades humanas sobre os sistemas naturais (BERTOSSI et al., 2013). A qualidade da água reflete as condições ambientais da bacia hidrográfica, sendo assim, conhecer essas características amplia o conhecimento ecológico do ecossistema e possibilita detectar alterações antrópicas (SOUZA \& GASTALDINI, 2014).

A manutenção das APPs, por exemplo, está diretamente relacionada com o menor carreamento de partículas e consequente manutenção da qualidade da água, sendo necessário para esse último aspecto, o uso do monitoramento. Algo importante a respeito das áreas ecologicamente frágeis (áreas declivosas, nascentes, margens dos rios e áreas de recarga dos aquíferos) é que muitas destas regiões são bacias vertentes do complexo sistema formador da drenagem de grandes rios, que fornecerão água para o abastecimento dos centros urbanos (OLIVEIRA et al., 2013).

Dessa forma é possível compreender a dinâmica dos processos naturais, exigindo no entanto um trabalho periódico feito ao longo de determinado tempo, levando anos em alguns casos até a produção de resultados conclusivos (PINTO et al., 2013). O monitoramento com menores intervalos de tempo é importante na verificação da dinâmica real da qualidade da água, tais como picos de concentração de nutrientes em horários específicos, podendo ajudar a compreender a variabilidade da qualidade da água ao longo do tempo. Um dos aspectos negativos desse tipo de técnica é o elevado número de amostras e também de análises laboratoriais (POTT et al., 2014).

$\mathrm{Na}$ determinação abrangente da qualidade da água o ideal seria ter um número virtualmente infinito de amostragens em pontos que fornecem dados espacialmente contínuos sobre a água qualidade, porém existem limitações práticas, tais como: restrições orçamentárias e manutenção das instalações utilizadas em campo (LEE et al., 2014). Em Nova York (EUA), para o monitoramento da turbidez da água são utilizadas estações robotizadas, sendo essa considerada uma evolução inestimável de recursos de gerenciamento para grandes sistemas de abastecimento de água preocupados com os efeitos da turbidez causada pelo carreamento de partículas (EFFLER et al., 2014).

Além das estações fixas utilizadas no monitoramento da qualidade da água, uma outra forma a ser utilizada é a modelagem. A modelagem matemática da qualidade da água está baseada no uso de equações que representam os processos de transporte e transformação de poluentes em corpos de água (FAN et al., 2013).

Vale ressaltar que no monitoramento da qualidade da água, é essencial o adequado controle de determinadas variáveis. Como resultado da variabilidade dos aspectos ambientais das sub-bacias, os aspectos a serem monitorados também serão diferentes (CHANG \& LIN, 2014).

A presença de fontes poluidoras em zonas urbanas é algo cada vez mais comum, estando as fontes de poluição divididas em pontuais e difusas. As fontes difusas são encontradas em bacias agrícolas ou urbanas geradoras de escoamento superficial, sendo essencial o conhecimento da origem espacial das cargas e de seus impactos negativos sobre a qualidade da água (BALTOKOSKI et al., 2010). Um 
exemplo para as fontes pontuais de poluição são os lançamentos de águas residuárias não tratadas. Como exemplos de constituintes responsáveis pela poluição da água, têm-se matéria orgânica, compostos nitrogenados e fosfatados, pesticidas e metais pesados (JING et al., 2013).

A escassez dos recursos hídricos tem se agravado e requer o emprego de medidas que visem a melhorar a gestão da oferta e da demanda de água para os diferentes usos. Assim, a manutenção do fornecimento de água, não só em quantidade suficiente, mas também com qualidade adequada, é um dos maiores desafios do século XXI (LOPES et al., 2014). Antes da captação da água utilizada para o abastecimento humano e industrial, é essencial conhecer a qualidade do manancial, aferida por meio de variáveis físicas, química e biológicas (BARRETO et al., 2014) que são monitoradas por meio de análises e exames laboratoriais.

A qualidade da água superficial é um dos principais fatores intervenientes na saúde pública, sendo que quando essa é captada para consumo humano ou industrial, deve seguir parâmetros estabelecidos em legislação nacional. O potencial Hidrogeniônico $(\mathrm{pH})$ e a condutividade são apontados como os dois principais parâmetros a serem monitorados em águas superficiais (ANA, 2014), porém os níveis de $\mathrm{P}$ total na água podem indicar contaminação por matéria orgânica, alguns elementos tais como $\mathrm{Ca}$, $\mathrm{Mg}, \mathrm{K}, \mathrm{Cu}, \mathrm{Fe}, \mathrm{Mn}, \mathrm{Zn}, \mathrm{Pb}, \mathrm{Cr}$ e Ni são indicadores de contaminações por metais pesados e o oxigênio dissolvido na água (OD) e a demanda bioquímica de oxigênio (DBO) também são outros indicadores de contaminação. Os níveis de turbidez indicam, por exemplo, quanto de material coloidal está em suspensão.

A turbidez da água indica sua transparência devido à existência de partículas coloidais em suspensão no meio aquoso. Os sólidos carreados pela chuva que causam o aumento da turbidez ocasionam impactos negativos, entre esses está a interrupção do abastecimento de água doméstico (YANG et al., 2014).

O monitoramento dessas partículas é algo importante nos processos de tratamento da água. Partículas de diferentes tamanhos estão presentes em águas naturais, mas colóides $(0,01$ e 0,1 mm) e pequenos sólidos (10 e $100 \mathrm{um}$ ) são as principais partículas a serem removidas em Estações de Tratamento de Água (ETAs) (YAO et al., 2014). Em países tais como a Finlândia, as determinações de turbidez na água são feitas com alta frequência. No ano de 2012, mais de 30.000 análises foram feitas nos lagos, rios e estuários do país. Para a medição da turbidez utiliza-se uma propriedade ótica da água, com base da dispersão da luz na amostra (NÄYKKI et al., 2014). A turbidez pode ser considerada como o parâmetro mais importante, entre todas as necessárias para determinar o estado da água. Esse parâmetro é largamente afetado pelos outros aspectos da água (IGLESIAS et al., 2014).

Relacionado aos níveis de matéria orgânica está a condutividade. Os dois métodos mais comuns para a realização das medições são os sensores de contato e os sensores indutivos (BANNA et al., 2014). A condutividade está relacionada com os íons dissolvidos na água. Águas subterrâneas e em áreas mais profundas, possuem maiores valores de condutividade elétrica (CE) pois estão em contato com as rochas. Devido aos maiores teores de íons dissolvidos, as águas poluídas possuem maiores valores de condutividade (PENG et al., 2014).

\section{Conclusões}

Em se tratando da busca por trabalhos que abordem adubos verdes em consórcio com nativas do Cerrado, não foram encontradas referências, ainda que o esgotamento das referências fosse algo buscado. Relativo à adubação verde e a melhoria de propriedades do solo após o consórcio com espécies de grande interesse comercial, muito têm sido feito. Também é frequente a publicação de trabalhos com o objetivo de compreender as interferências no uso do solo sobre a qualidade da água.

\section{Agradecimentos}

Nossos agradecimentos especiais à Fundação de Amparo à Pesquisa do Estado de Goiás (FAPEG). 


\section{Referências}

AGHILI, F.; GAMPER, H. N.; EIKENBERG, J.; KHOSHGOFTARMANESH, A. H.; AFYUNI, M.; SCHULIN, R.; JANSA, J.; FROSSARD, E. Green Manure Addition to Soil Increases Grain Zinc Concentration in Bread Wheat. PLoS One, USA, v. 9, Issue 7, p. 1-13, Jul. 2014.

AGUIAR, L. M. S.; BERNARD, E.; MACHADO, R. B. Habitat use and movements of Glossophaga soricina and Lonchophylla dekeyseri (Chiroptera: Phyllostomidae) in a Neotropical savannah. Zoologia, Curitiba, v. 31, n. 3, p. 223-229, maio/jun. 2014.

AJAllA, A. C. A.; VOLPE, E.; VIEIRA, M. C.; ZÁRATE, N. A. H. Produção de mudas de baru (Dipteryx alata Vog.) sob três níveis de sombreamento e quatro classes texturais de solo. Revista Brasileira de Fruticultura, Jaboticabal, v. 34, n. 3, p. 888-896, set. 2012.

AMBROSANO, E. J.; CANTARELLA, H.; AMBROSANO, G. M. B.; SCHAMMAS, E. A; DIAS, F. L. F.; ROSSI, F.; TRIVELIN, P. C. O.; MURAOKA, T.; SACHS, R. C. C.; AZCÓN, R. Produtividade da cana-de-açúcar após o cultivo de leguminosas. Bragantia, Campinas, v. 70, n. 4, p. 810-818, 2011.

ANA - Agência Nacional de Águas. Portal da qualidade da água. Padrões de qualidade rede de monitoramento. Disponível em: <http://pnqa.ana.gov.br/rede/rede_monitoramento.aspx.>. Acesso em 01 nov. 2014.

ARAUJO, I. C. L.; DZIEDZIC, M.; MARANHO, L. T. Management of the environmental restoration of degraded areas. Brazilian Archives of Biology and Technology, Curitiba, v. 57, n. 2, p. 284-294, mar./abr. 2014.

ASSUNÇÃO, V. A.; GUGLIERI-CAPORAL, A.; SARTORI, A. L. B. Florística do estrato herbáceo de um remanescente de cerradão em Campo Grande, Mato Grosso do Sul, Brasil. Hoehnea, São Paulo, v. 38, n. 2, p. 281-288, jun. 2011.

AVANZI, J. C.; SILVA, M. L. N.; CURI, N.; NORTON, L. D.; BESKOW, S.; MARTINS, S. G. Spatial distribution of water erosion risk in a watershed with eucalyptus and Atlantic Forest. Ciência e Agrotecnologia, Lavras, v. 37, n. 5, 427-434, set./out. 2013.

BALTOKOSKI, V.; TAVARES, M. H. F.; MACHADO, R. E.; OLIVEIRA, M. P. Calibração de modelo para a simulação de vazão e de fósforo total nas sub-bacias dos Rios Conrado e Pinheiro - Pato Branco (PR). Revista Brasileira de Ciência do Solo, Viçosa, v. 34, n. 1, p. 253-261, jan./fev. 2010.

BANNA, M. H.; NAJJARAN, H.; SADIQ, R.; IMRAN, S. A.; RODRIGUEZ, M. J.; HOORFAR, M. Miniaturized water quality monitoring $\mathrm{pH}$ and conductivity sensors. Sensors and Actuators B: Chemical, USA, v. 193, p. 434-441, Mar. 2014.

BARRETO, L. V.; FRAGA, M. C.; BARROS, F. M.; ROCHA, F. A.; AMORIM, J. S.; CARVALHO, S. R.; BONOMO, P.; SILVA, D. P. Relação entre vazão e qualidade da água em uma seção de rio. Revista Ambiente \& Água, Taubaté, v. 19, n. 1, p. 118-129, jan./mar. 2014.

BARRINGTON, D. J.; GHADOUANI, A.; SINANG, S. C.; IVEY, G. N. Development of a new riskbased framework to guide investment in water quality monitoring. Environmental Monitoring and Assessment, v. 186, Issue 4, p. 2455-2464, Dec. 2013.

BAUER, D.; GOETZ, M. N. B.; MÜLLER, A.; SCHMITT, J. L. Fenologia de três espécies de Myrsine 1. em floresta secundária semidecídua no Sul do Brasil. Revista Árvore, Viçosa, v. 36, n. 5, p. 859-868, set./out. 2012.

BERTOL, I.; RAMOS, R. R.; BARBOSA, F. T.; GONZÁLEZ, A. P.; RAMOS, J. C.; BANDEIRA, D. H. Water erosion in no-tillage monoculture and intercropped systems along contour lines. Revista Brasileira de Ciência do Solo, Viçosa, v. 37, n. 2, p. 521-528, mar./abr. 2013. 
BERTOSSI, A. A. A.; CECÍlIO, R. A.; NEVES, M. A.; GARCIA, G. O. Qualidade da água em microbacias hidrográficas com diferentes coberturas do solo no sul do Espírito Santo. Revista Árvore, v. 37, n. 1, p. 107-117, jan./fev. 2013.

BRASIL. Lei de № 12.651, de 25 de maio de 2012. Dispõe sobre a proteção da vegetação nativa; altera as Leis nos 6.938, de 31 de agosto de 1981, 9.393, de 19 de dezembro de 1996, e 11.428, de 22 de dezembro de 2006; revoga as Leis nos 4.771, de 15 de setembro de 1965, e 7.754, de 14 de abril de 1989, e a Medida Provisória no 2.166-67, de 24 de agosto de 2001; e dá outras providências. Disponível em: <http://www.planalto.gov.br/ccivil_03/_ato2011-2014/2012/lei/112651.htm>. Acesso em: 25 dez. 2014.

BRUGGEMAN, D.; MEYFRODIT, P.; LAMBIN, E. F. Production forests as a conservation tool: Effectiveness of Cameroon'sland use zoning policy. Land Use Policy-Elsevier, USA, v. 42, p. 151164, Jan. 2015.

BONO, J. A. M.; MACEDO, M. C. M.; TORMENA, C. A. Qualidade física do solo em um latossolo vermelho da região sudoeste dos cerrados sob diferentes sistemas de uso e manejo. Revista Brasileira de Ciência do Solo, Viçosa, v. 37, n. 3, p. 743-753, maio/jun. 2013.

BOUMAN, O. T. Tree diversity in 30-year chronosequences of cool-humid forests. Ecological Indicators-Elsevier, USA, v. 49, p. 32-38, Feb. 2015.

BOUTILIER, M. S. H.; LEE, J.; CHAMBERS, V.; VENKATESH, V.; KARNIK, R. Water Filtration Using Plant Xylem. Plos One, USA, v. 9, Issue 2, p. 1-8, Feb. 2014.

CAMPOS, M. L.; GUILHERME, L. R. G.; MARQUES, J. J. G. S. M.; CURI, N.; ARAÚJO, A. S. A.; MIQUELLUTI, D. J.; LOPES, C.; SPIAZZI, F. R. Teores de arsênio e cádmio em solos do bioma cerrado. Revista Brasileira de Ciência do Solo, Viçosa, v. 37, n. 1, p. 281-286, jan./fev. 2013.

CARDOSO, D. P.; SILVA, M. L. N.; CARVALHO, G. J.; FREITAS, D. A. F.; AVANZI, J. C. Plantas de cobertura no controle das perdas de solo, água e nutrientes por erosão hídrica. Revista Brasileira de Engenharia Agrícola e Ambiental, Campina Grande, v. 16, n. 6, p. 632-638, jun. 2012.

CARTER, M. S.; SORENSEN, P.; PETERSEN, S. O.; MA, X.; AMBUS, P. Effects of green manure storage and incorporation methods on nitrogen release and $\mathrm{N} 2 \mathrm{O}$ emissions after soil application. Biology and Fertility of Soils, USA, v. 50, Issue 8, p. 1233-1246, Nov. 2014.

CARVALHO, A. M.; MARCHÃO, R. L.; SOUZA, K. W.; BUSTAMANTE, M. M. C. Soil fertility status, carbon and nitrogen stocks under cover crops and tillage regimes. Revista Ciência Agronômica, Fortaleza, v. 45, n. 5, p. 914-921, 2014.

CHANG, C-L \& LIN, Y-T. A water quality monitoring network design using fuzzy theory and multiple criteria analysis. Environmental Monitoring and Assessment, v. 186, Issue 10, p. 64596469, Jun. 2014.

CORDEIRO, T. T. S.; FERREIRA, E. M.; RODRIGUES, V. J. O. Contenção de erosão em Área de Preservação Permanente (APP). Enciclopédia Biosfera, Goiânia, v. 10, n. 18, p. 1032-1041, 2014.

COSTA, C. H. M.; CRUSCIOL, C. A. C.; SORATTO, R. P.; FERRARI NETO, J. Persistência e liberação de elementos da fitomassa do consórcio crotalária com milheto sob fragmentação. Revista Ciência Agronômica, Fortaleza, v. 45, n. 1, p. 197-208, jan./mar. 2014.

DARONCO, C.; MELO, A. C. G.; DURIGAN, G. Ecossistema em restauração versus ecossistema de referência: estudo de caso da comunidade vegetal de mata ciliar em região de Cerrado, Assis, SP, Brasil. Hoehnea, São Paulo, v. 40, n. 3, p. 485-498, set. 2013.

EFFLER, S. W.; O'DONNELL, D. M.; PRESTIGIACOMO, A. R.; PIERSON, D. C.; ZION, M. S.; PYKE, G. W.; WEISS, W. J. Robotic Monitoring for Turbidity Management in Multiple Reservoir Water Supply. Journal of Water Resources Planning and Management, USA, v. 140, Issue 7, p. 04014007, Jul. 2014. 
FAN, F. M.; COLLISCHONN, W.; RIGO, D. Modelo analítico de qualidade da água acoplado com Sistema de Informação Geográfica para simulação de lançamentos com duração variada. Engenharia Sanitaria e Ambiental, Rio de Janeiro, v. 18, n. 4, p. 359-370, out./dez. 2013.

FERREIRA, R. A.; AGUIAR NETTO, A. O.; SANTOS, T. I. S.; SANTOS, B. L.; MATOS, E. L. Nascentes da sub-bacia hidrográfica do rio Poxim, estado de Sergipe: da degradação à restauração. Revista Árvore, Viçosa, v. 35, n. 2, p. 265-277, mar./abr. 2011. a.

FERREIRA, E. P. B.; WENDLAND, A.; DIDONET, A. D. Microbial biomass and enzyme activity of a Cerrado Oxisol under agroecological production system. Bragantia, Campinas, v. 70, n. 4, p. 899907, 2011b.

FINA, B. G \& MONTEIRO, R. Análise da estrutura arbustivo-arbórea de uma área de cerrado sensu stricto, município de Aquidauana-Mato Grosso do Sul. Revista Árvore, Viçosa, v. 37, n. 4, p. 577585, jul./ago. 2013.

FRANÇOSO, R.; GUARALDO, A. C.; PRADA, M.; PAIVA, A. O.; MOTA, E. H.; PINTO, J. R. R. Fenologia e produção de frutos de Caryocar brasiliense Cambess. E Enterolobium gummiferum (Mart.) J.F.Macbr. em diferentes regimes de queima. Revista Árvore, Viçosa, v. 38, n. 4, p. 579-590, jul./ago. 2014.

GITTI, D. C.; ARF, O.; PORTUGAL, J. R.; CORSINI, D. C. D. C.; RODRIGUES, R. A. F.; KANEKO, F. H. Coberturas vegetais, doses de nitrogênio e inoculação de sementes com Azospirillum brasilense em arroz de terras altas no sistema plantio direto. Bragantia, Campinas, v. 71, n. 4, p. 509-517, 2012 Epub 08-Jan-2013.

GUILLOZET, P.; SMITH, K.; GUILLOZET, K. The rapid riparian revegetations approach. Project Muse, Maryland USA, v. 32, n. 2, p. 113-124, Jun. 2014.

HIRATA, A. C. S.; HIRATA, E. K.; GUIMARÃES, E. C.; RÓS, A. B.; MONQUERO, P. A. Plantio direto de alface americana sobre plantas de cobertura dessecadas ou roçadas. Bragantia, Campinas, v. 73, n. 2, p. 178-183, abr.jun. 2014.

HU, Y-X.; HUANG, J-L.; DU, Y.; HAN, P. P.; WANG, J. L.; HUANG, W. Monitoring wetland vegetation pattern response to water-level change resulting from the Three Gorges Project in the two largest freshwater lakes of China. Ecological Engineering-Elsevier, USA, v. 74, p. 274-285, Jan. 2015.

HUNINK, J. E.; DROOGERS, P.; KAUFFMAN, S.; MWANIKI, B. M.; BOUMA, J. Quantitative simulation tools to analyze up- and downstream interactions of soil and water conservation measures: Supporting policy making in the Green Water Credits program of Kenya. Journal of Environmental Management-Elsevier, USA, v. 111, p. 187-194, Epub 2012 Aug 21.

IGLESIAS, C.; TORRE, J. M.; GARCÍA NIETO, P. J.; FERNÁNDEZ, J. R. A.; MUÑIZ, C. D.; PIÑEIRO, J. I.; TABOABA, J. Turbidity Prediction in a River Basin by Using Artificial Neural Networks: A Case Study in Northern Spain. Water Resources Management, USA, v. 28, Issue 2, p. 319-331, Jan. 2014.

INPA - Instituto Nacional de Pesquisas da Amazônia. Adubação verde é técnica eficiente para aumentar a produção agrícola na região, especialmente de hortaliças, outubro de 2013. Disponível em: <http://www.inpa.gov.br/noticias/noticia_sgno2.php?codigo=3018>. Acesso em: 25 dez. 2014.

JING, G.; WANG, L.; YU, H.; AMER, W. A.; ZHANG, L. Recent progress on study of hybrid hydrogels for water treatment. Colloids and Surfaces A: Physicochemical and Engineering Aspects, USA, v. 416, p. 86-94, Jan. 2013.

JOHNSTON, C. A. Agricultural expansion: land use shell game in the U.S. Northern Plains. Landscape Ecology, USA, v. 29, Issue 1, p. 81-95, Jan. 2014. 
KUWANO, B. H.; KNOB, A.; FAGOTTI, D. S. L.; MELÉM JÚNIOR, N. J.; GODOY, L.; DIEHL, R. C.; KRAWULSKI, C. C.; ANDRADE FILHO, G.; ZANGARO FILHO, W.; TAVARES-FILHO, J.; NOGUEIRA, M. A. Soil quality indicators in a rhodic kandiudult under different uses in northern Parana, Brazil. Revista Brasileira de Ciência do Solo, Viçosa, v. 38, n. 1, p. 50-59, jan./fev. 2014.

LAURANCE, W. F.; SAYER, J.; CASSMAN, K. G. Agricultural expansion and its impacts on tropical nature. Trends in Ecology and Evolution, USA, v. 29, Issue 2, p. 107-116, Feb. 2014.

LEAL, A. J. F.; LAZARINI, E.; RODRIGUES, L. R.; MARCANDALLI, L. H. Adubação nitrogenada para milho com o uso de plantas de cobertura e modos de aplicação de calcário. Revista Brasileira de Ciência do Solo, v. 37, n. 2, p. 491-501, mar./abr. 2013.

LEE, C.; PAIK, K.; YOO, D. G.; KIM, J. H. Efficient method for optimal placing of water quality monitoring stations for an ungauged basin. Journal of Environmental Management, USA, v. 132, pages. 24-31, Jan. 2014.

LEITE, L. F. C.; ARRUDA, F. P.; COSTA, C. N.; FERREIRA, J. S.; HOLANDA NETO, M. R. Qualidade química do solo e dinâmica de carbono sob monocultivo e consórcio de macaúba e pastagem. Revista Brasileira de Engenharia Agrícola e Ambiental, Campina Grande, v. 17, n. 12, p. 12571263, dez. 2013.

LIMA, J. S. S.; SOUZA, G. S.; SILVA, S. A. Distribuição espacial da matéria orgânica, grau de floculação e argila dispersa em água em área de vegetação natural em regeneração e pastagem. Revista Árvore, Viçosa, v. 37, n. 3, p. 539-546, maio/jun. 2013.

LIMA, A. A.; FERNANDES JÚNIOR, P. I.; PASSOS, S. R.; PAULO, F. S.; NOSOLINE, S. M.; FARIA, S. M.; GUERRA, J. G. M.; RUMJANEK, N. G.; XAVIER, G. R. Diversidade e capacidade simbiótica de rizóbios isolados de nódulos de Mucuna-Cinza e Mucuna-Anã. Revista Brasileira de Ciência do Solo, Viçosa, v. 36, n. 2, p. 337-348, mar./abr. 2012.

LU, C-X.; YU, G.; XIAO, Y.; XIE, G-D. Wind tunnel simulation and evaluation of soil conservation function of alpine grassland in Qinghai-Tibet Plateau. Ecological Economics-Elsevier, USA, v. 86, pages 16-20, Feb. 2013.

LOPES, F. B.; ANDRADE, E. M.; MEIRELES, A. C. M.; BECKER, H.; BATISTA, A. A. Assessment of the water quality in a large reservoir in semiarid region of Brazil. Revista Brasileira de Engenharia Agrícola e Ambiental, Campina Grande, v. 18, n. 4, p. 437-445, abr. 2014.

MADALÃO, J. C.; PIRES, F. R.; CARGNELUTTI FILHO, A.; NASCIMENTO, A. F.; CHAGAS, K.; ARAÚJO, R. S.; PROCÓPIO, S. O.; BONOMO, R. Susceptibilidade de espécies de plantas com potencial de fitorremediação do herbicida sulfentrazone. Revista Ceres, Viçosa, v. 60, n. 1, p. 111121, jan./fev. 2013.

MAGALHÃES, S. S. A.; WEBER, O. L. S.; SANTOS, C. H.; VALADÃO, F. C. A. Estoque de nutrientes sob diferentes sistemas de uso do solo de Colorado do Oeste-RO. Acta Amazonica, Manaus, v. 43, n. 1, p. 63-72, mar. 2013.

MARCOS, P. F \& PESSÔA, V. L. S. O agronegócio no cerrado do Sudeste Goiano: uma leitura sobre Campo Alegre de Goiás, Catalão e Ipameri. Sociedade \& Natureza, v. 24, n. 1, p. 37-49, jan./abr. 2012.

MARIOTI, J.; BERTOL, I.; RAMOS, J. C.; WERNER, R. S.; PADILHA, J.; BANDEIRA, D. H. Erosão hídrica em semeadura direta de milho e soja nas direções da pendente e em contorno ao declive, comparada ao solo sem cultivo e descoberto. Revista Brasileira de Ciência do Solo, Viçosa, v. 37, n. 5, p. 1361-1371, set./out. 2013.

MATOS, P. F \& PESSÔA, V. L. S. O agronegócio no cerrado do Sudeste Goiano: uma leitura sobre Campo Alegre de Goiás, Catalão e Ipameri. Sociedade \& Natureza, Uberlândia, v. 24, n. 1, p. 37-49, jan./abr. 2012. 
MELERO, M. M.; GITTI, D. C.; ARF, O.; RODRIGUES, R. A. F. Coberturas vegetais e doses de nitrogênio em trigo sob sistema plantio direto. Pesquisa Agropecuária Tropical, Goiânia, v. 43, n. 4, p. 343-353, out./dez. 2013.

MIRANDA, A. C. R.; SILVA, D. P.; MELLO, E. L.; PRUSKI, F. F. Assessment of Efficiency and Adequacy of Retention Terraces. Revista Brasileira de Ciência do Solo, Viçosa, v. 36, n. 2, p. 577586, mar./abr. 2012.

MIRANDA, D. L. C.; MELO, A. C. G.; SANQUETTA, C. R. Equações alométricas para estimativa de biomassa e carbono em árvores de reflorestamentos de restauração. Revista Árvore, Viçosa, v. 35, n. 3, p. 679-689, maio/jun. 2011.a.

MIRANDA, L. P. M.; TARSITANO, M. A. A.; ALVES, M. C.; RODRIGUES, R. A. F. Custo para implantação de Astronium fraxinifolium schott em área degradada utilizando-se adubos verdes e lodo de esgoto. Pesquisa Agropecuária Tropical, Goiânia, v. 41, n. 4, p. 475-480, out./dez. 2011b.

MONQUERO, P. A.; CÔRREA, M. C.; BARBOSA, L. N.; GUTIERREZ, A.; ORZARI, I.; HIRATA, A. C. S. Seleção de espécies de adubos verdes visando à fitorremediação de diclosulam. Planta Daninha, Viçosa, v. 31, n. 1, p. 127-135, jan./mar. 2013.

MORAIS, L. A. S \& BARBOSA, A. G. Influência da adubação verde e diferentes adubos orgânicos na produção de fitomassa aérea de atroveran (Ocimum selloi Benth.). Revista Brasileira de Plantas Medicinais, Botucatu, v. 14, n. spe. p. 246-249, 2012.

MOREIRA, C.; RAMOS, R.; AZEVEDO, J.; VASCONCELOS, V. Methods to detect cyanobacteria and their toxins in the environment. Applied Microbiology and Biotechnology, USA, v. 98, Issue 19, pp. 8073-8082, Oct. 2014.

NÄYKKI, T.; KOPONEN, S.; VÄISÄNEN, T.; PYHÄLAHTI, T.; TOIVANEN, T.; LEITO, I. Validation of a new measuring system for water turbidity field measurements. Accreditation And Quality Assurance, USA, v. 19, Issue 3, p. 175-183, Ap. 2014.

NERI, A. V.; SCHAEFER, C. E. G. R.; SOUZA, A. L.; FERREIRA-JUNIOR, W. G.; MEIRA-NETO, J. A. A. Pedology and plant physiognomies in the cerrado, Brazil. Anais da Academia Brasileira de Ciências, Rio de Janeiro, v. 85, n. 1, p. 87-102, mar. 2013.

NUNES, R. S.; SOUSA, D. M. G.; GOEDERT, W. J.; VIVALDI, L. J. Distribuição de fósforo no solo em razão do sistema de cultivo e manejo da adubação fosfatada. Revista Brasileira de Ciência do Solo, Viçosa, v. 35, n. 3, p. 877-888, maio/jun. 2011.

OLIVIERA, A. C. S.; COELHO, F. C.; CREVELARI, J. A.; FERNANDES, I. S.; RUBIM, R. F. Fitossociologia de plantas daninhas em monocultivo de milho e em consórcio com diferentes Fabaceae. Revista Ceres, Viçosa, v. 61, n. 5, p. 643-651, set./out. 2014.

OLIVEIRA, E. G.; FERREIRA, M. E.; ARAÚJO, F. M. Diagnóstico do uso da terra na região CentroOeste de Minas Gerais, Brasil: a renovação da paisagem pela cana-de-açúcar e seus impactos socioambientais. Sociedade \& Natureza, v. 24, n. 3, p. 545-555, set./dez. 2012.

OLIVEIRA, J. R.; PINTO, M. F.; SOUZA, W. J.; GUERRA, J. G. M.; CARVALHO, D. F. Erosão hídrica em um Argissolo Vermelho-Amarelo, sob diferentes padrões de chuva simulada. Revista Brasileira de Engenharia Agrícola \& Ambiental, Campina Grande, v. 14, n. 2, p. 140-147, fev. 2010.

OLIVEIRA, L. F. C.; CALIL, P. M.; RODRIGUES, C.; KLIEMANN, H. J.; OLIVEIRA, V. A. Potencial do uso dos solos da bacia hidrográfica do alto rio Meia Ponte, Goiás. Revista Ambiente \& Água, Taubaté, v. 8, n. 1, p. 222-238, jan./abr. 2013.

PAIVA, A. O.; REZENDE, A. V.; PEREIRA, R. S. Estoque de carbono em cerrado sensu stricto do Distrito Federal. Revista Árvore, Viçosa, v. 35, n. 3, p. 527-538, maio/jun. 2011. 
PENG, T-R.; LU, W-C.; CHEN, K-Y.; ZHAN, W-J.; LIU, T-K. Groundwater-recharge connectivity between a hills-and-plains' area of western Taiwan using water isotopes and electrical conductivity. Journal of Hydrology, USA, v. 517, p. 226-235, Sep. 2014.

PERAZZOLI, M.; PINHEIRO, A.; KAUFMANN, V. Efeitos de cenários de uso do solo sobre o regime hidríco e produção de sedimentos na bacia do Ribeirão Concórdia - SC. Revista Árvore, Viçosa, v. 37, n. 5, p. 859-869, set./out. 2013.

PINHEIRO, A.; KAUFMANN, V.; SHNEIDERS, D.; GOTARDO, R. Transporte de sedimentos e espécies químicas em áreas de reflorestamentos e pastagem com base em chuva simulada. Revista Ambiente \& Água, Taubaté, v. 8, n. 2, p. 109-123, maio/ago. 2014.

PINTO, L. C.; DE MELLO, C. R.; ÁVILA, L. F. Water quality indicators in the Mantiqueira Range region, Minas Gerais state. Cerne, Lavras, v. 19, n. 4, p. 687-692, out./dez. 2013.

POTT, C. A.; JADOSKI, S. O.; SCHMALZ, B.; HÖRMANN, G.; FOHRER, N. Temporal variability of nitrogen and phosphorus concentrations in a German catchment: Water sampling implication. Revista Brasileira de Engenharia Agrícola e Ambiental, Campina Grande, v. 18, n. 8, p. 811-818, ago. 2014.

PORTELA, J. C.; COGO, N. P.; BAGATINI, T.; CHAGAS, J. P.; PORTZ, G. Restauração da estrutura do solo por sequências culturais implantadas em semeadura direta, e sua relação com a erosão hídrica em distintas condições físicas de superfície. Revista Brasileira de Ciência do Solo, Viçosa, v. 34, n. 4, p. 1353-1364, jul./ago. 2010.

POEPLAU, C \& DON, A. Carbon sequestration in agricultural soils via cultivation of cover crops - A meta-analysis. Agriculture, Ecosystems and Environment-Elsevier, USA, v. 200, p. 33-41, Feb. 2015.

ROSENDO, J. S. \& ROSA, R. Comparação do estoque de C estimado em pastagens e vegetação nativa de Cerrado. Sociedade \& Natureza, Uberlândia, v. 24, n. 2, p. 359-376, maio/ago. 2012.

ROSOLEN, V.; RESENDE, T. M.; BORGES, E. N.; FRARE, C. T.; MACHADO, H. M. Variações nos teores do $\mathrm{C}$ total e isotópico do solo após substituição do Cerrado em sistemas agrícolas no Triângulo Mineiro. Sociedade \& Natureza, Uberlândia, v. 24, n. 1, p. 157-167, jan./abr. 2012.

SAUER, S \& LEITE, S. P. Expansão agrícola, preços e apropriação de terra por estrangeiros no Brasil. Revista de Economia e Sociologia Rural, Brasília, v. 50, n. 3, p. 503-524, jul./set. 2012.

SHRESTHA, K.; STEVENS, S.; SHRESTHA, P.; ADETUTU, E. M.; WALSH, K. B.; BALL, A. S.; MIDMORE, D. J. Characterisation of the soil microbial community of cultivated and uncultivated vertisol in Australia under several management regimes. Agriculture, Ecosystems and Environment-Elsevier, USA, v. 199, p. 418-427, Jan. 2015.

SHI, Z. H.; AI, L.; FANG, N. F.; ZHU, H. D. Modeling the impacts of integrated small watershed management on soil erosion and sediment delivery: A case study in the Three Gorges Area, China. Journal of Hydrology-Elsevier, USA, v. 438-439, pages 156-167. 17 May. 2012.

SILVA, A. M.; MORAES, M. L. T.; BUZETTI, S. Propriedades químicas de solo sob reflorestamento ciliar após 20 anos de plantio em área de cerrado. Revista Árvore, Viçosa, v. 35, n. 1, p. 97-106, jan./fev. 2011.

; SILVA, C. A.; SILVA, I. R.; MARQUES, J. J. G. S. M.; ARAUJO, E. F.; CARVALHO, S. A.; SILVA, S. H. G.; CURI, N. Frações de carbono em topossequências de solos sob eucalipto com diferentes históricos de uso. Revista Brasileira de Ciência do Solo, Viçosa, v. 36, n. 34, p. 11671178, jul./ago. 2012.

SORATTO, R. P.; CRUSCIOL, C. A. C.; COSTA, C. H. M.; FERRARI NETO, J.; CASTRO, G. S. A. Produção, decomposição e ciclagem de nutrientes em resíduos de crotalária e milheto, cultivados 
solteiros e consorciados. Pesquisa Agropecuária Brasileira, Brasília, v. 47, n. 10, p. 1462-1470, out. 2012.

SOUSA, C. S.; MENEZES, R. S. C.; SAMPAIO, E. V. S. B.; OEHL, F.; MAIA, L. C.; GARRIDO, M. S.; LIMA, F. S. Occurrence of arbuscular mycorrhizal fungi after organic fertilization in maize, cowpea and cotton intercropping systems. Acta Scientiarum Agronomy, Maringá, v. 34, n. 2, p. 149-156, abr./jun. 2012.

SOUZA, M. M \& GASTALDINI, M. C. C. Avaliação da qualidade da água em bacias hidrográficas com diferentes impactos antrópicos. Engenharia Sanitária e Ambiental, Rio de Janeiro, v. 19, n. 3, p. 263-274, jul./set. 2014.

TAVARES, W.S.; CRUZ, I.; SILVA, R.B.; FIGUEIREDO, M.L.C.; RAMALHO, F.S.; SERRÃO, J.E.; ZANUNCIO, J. C. Soil organisms associated to the weed suppressant Crotalaria juncea (fabaceae) and its importance as a refuge for natural enemies. Planta Daninha, Viçosa, v. 29, n. 3, p. 473-479, jul./set. 2011.

TEODORO, R. B.; OLIVIERA, F. L.; SILVA, D. M. N.; FÁVERO, C.; QUARESMA, M. A. L. Leguminosas herbáceas perenes para utilização como coberturas permanentes de solo na Caatinga Mineira. Revista Ciência Agronômica, Fortaleza, v. 42, n. 2, p. 292-300, abr./jun. 2011.

; OLIVEIRA, F. L.; SILVA, D. M. N.; FÁVERO, C.; QUARESMA, M. A. L. Aspectos agronômicos de leguminosas para adubação verde no Cerrado do Alto Vale do Jequitinhonha. Revista Brasileira de Ciência do Solo, Viçosa, v. 35, n. 2, p. 635-640, mar./abr. 2011.

TIMOSSI, P. C.; WISINTAINER, C.; SANTOS, B. J.; PEREIRA, V. A.; PORTO, V. S. Supressão de plantas daninhas e produção de sementes de crotálaria, em função de métodos de semeadura. Pesquisa Agropecuária Tropical, Goiânia, v. 41, n. 4, p. 525-530, out./dez. 2011.

TOLEDO, D. S.; COSTA, C. A.; BACCI, L.; FERNANDES, L. A.; SOUZA, M. F. Production and quality of tomato fruits under organic management. Horticultura Brasileira, Brasília, v. 29, n. 2, p. 253-257, abr./jun. 2011.

TRANCOSO, R.; SANO, E. E.; MENESES, P. R. The spectral changes of deforestation in the Brazilian tropical Savana. Environmental Monitoring and Assessment-Springer, USA, v. 187, p. 1-15, Dec. 2014.

TUAN, S-E.; LI, N-J.; YEH, C-C.; TANG, L-C.; CHI, H. Effects of Green Manure Cover Crops on Spodoptera litura (Lepidoptera: Noctuidae) Populations. Journal of Economic Entomology, v. 107, n. 3, p. 896-905, Dec. 2014.

VARGAS, T. O.; DINIZ, E. R.; SANTOS, R. H. S.; URQUIAGA, S.; CECON, P. R. Nitrogen contributions of legume roots to cabbage nutrition. Scientia Agricola, Piracicaba, v. 70, n. 6, p. 415421, nov./dez. 2013.

LIMA, C. T. A.; URQUIAGA, S.; ___ Influência da biomassa de leguminosas sobre a produção de repolho em dois cultivos consecutivos. Horticultura Brasileira, Brasília, v. 29, n. 4, p. 562-568, out./dez. 2011.

VENTUROLI, F.; FELFILI, J. M.; FAGG, C. W. Avaliação temporal da regeneração natural em uma floresta estacional semidecídua secundária, em Pirenópolis, Goiás. Revista Árvore, Viçosa, v. 35, n. 3, p. 473-483, maio/jun. 2011.

VIEIRA, P. A.; FERREIRA, N. C.; FERREIRA, L. G. Análise da vulnerabilidade natural da paisagem em relação aos diferentes níveis de ocupação da bacia hidrográfica do Rio Vermelho, estado de Goiás. Sociedade \& Natureza, Uberlândia, v. 26, n. 2, p. 385-400, maio/ago. 2014.

VOLK, L. B. S \& COGO, N. P. Erosão hídrica, em três momentos da cultura do milho, influenciada por métodos de preparo do solo e semeadura. Revista Brasileira de Ciência do Solo, Viçosa, v. 38, n. 2, p. 565-574, mar./abr. 2014. 
YANG, T-M.; FAN, S-K.; FAN, C.; HSU, N-S. Establishment of turbidity forecasting model and earlywarning system for source water turbidity management using backpropagation artificial neural network algorithm and probability analysis. Environmental Monitoring and Assessment, USA, v. 186, Issue 8, p. 4925-4934, Aug. 2014.

YAO, M.; NAN, J.; CHEN, T. Effect of particle size distribution on turbidity under various water quality levels during flocculation processes. Desalination, USA, v. 354, p. 116-124, Dec. 2014.

WAUTERS, E.; BIELDERS, C.; POESEN, J.; GOVERS, G.; MATHIJS, E. Adoption of soil conservation practices in Belgium: An examination of the theory of planned behavior in the agri-environmental domain. Land Use Policy-Elsevier, USA, v. 27, Issue 1, pages 86-94, January 2010.

ZANCHETA, A. C. F.; ABREU, C. A.; ZAMBROSI, F. C. B.; ERISMANN, N. M.; LAGÔA, A. M. M. A. Fitoextração de cobre por espécies de plantas cultivadas em solução nutritiva. Bragantia, Campinas, v. 70, n. 4, p. 737-744, 2011. 